\title{
O DIREITO AO ESQUECIMENTO NO ORDENAMENTO JURÍDICO BRASILEIRO: A TUTELA DE UM DIREITO CONSTITUCIONAL DA PERSONALIDADE EM FACE DA SOCIEDADE DA INFORMAÇÃO ${ }^{1}$
}

\author{
Kamyla Raiana Maciel Castelo Branco ${ }^{2}$ \\ Faculdade Santo Agostinho - UNIFSA \\ Andréia Nádia Lima de Sousa Pessoa ${ }^{3}$ \\ Universidade Estadual do Piauí - UESPI \\ Paulo Rangel Araújo Ferreira ${ }^{4}$ \\ Universidade Federal do Piauí - UFPI \\ Pollyana Rodrigues Leal $^{5}$ \\ Faculdade Santo Agostinho - UNIFSA
}

\begin{abstract}
RESUMO
O estudo tem como objetivo analisar a questão do conflito existente entre o direito ao esquecimento e a liberdade de informação, de expressão e de imprensa. Para sua realização utilizou-se o método indutivo visando alcançar meios possíveis de solução dos conflitos existentes entre normas de mesmo grau hierárquico. Os resultados mostraram que o direito ao esquecimento, alicerçado sobre o princípio da dignidade da pessoa humana, assegura à pessoa que se veja constrangida por fatos passados, mesmo que verídicos, possa impedir que os mesmos venham ou permaneçam públicos. A proteção dos dados é de imensurável importância e merece ser tratada com maior atenção pelo ordenamento jurídico brasileiro. Destacando que a aplicabilidade desse direito depende da solicitação de quem se sente lesado e acredita possuir o direito de ser esquecido. Concluindo, assim, que a solução para os conflitos dos direitos se encontram na ponderação e na razoabilidade.
\end{abstract}

Palavras-Chave: Direitos humanos. Direito ao esquecimento. Sociedade da informação. Conflitos de direitos.

\section{INTRODUÇÃO}

Atualmente é provado o fundamental e insubstituível papel que a imprensa realiza na sociedade moderna. Em um Estado Democrático de Direito a liberdade de imprensa, enquanto projeção da liberdade de informação e de expressão encontra-se em um estágio de suma importância, dominando um significado de direito fundamental universalmente garantido. Dessa forma, resta comprovada a importância que possui a imprensa na evolução e consolidação de uma

\footnotetext{
${ }^{1}$ Trabalho apresentado no Congresso Brasileiro Ciência e Sociedade (CBCS 2019), promovido pelo Centro Universitário Santo Agostinho, de 03 a 05 de outubro de 2019, em Teresina-PI.

${ }^{2}$ Bacharel em Direito pela Faculdade Santo Agostinho, E-mail: kamyla.branco@trf1.jus.br;

${ }^{3}$ Mestre em Direito pela Universidade Católica de Brasília - UCB; Professora da Universidade Estadual do Piauí (UESPI) e da Faculdade Santo Agostinho; E-mail: andreianadia@hotmail.com;

${ }^{4}$ Mestre em Filosofia pela Universidade Federal do Piauí - UFPI; E-mail: araujo_rangel@hotmail.com;

${ }^{5}$ Bacharel em Direito pela Faculdade Santo Agostinho, E-mail: pollyana.leal@hotmail.com. 


\section{CONGQEESSOCIENCIAESOCIEDADE

democracia, buscando-se desde o advento da Constituição Federal de 1988, por uma imprensa de fato livre, não subordinada a qualquer tipo de censura.

Por outro lado, também de índole constitucional, estão os direitos da personalidade, que podem ser entendidos como aqueles direitos derivados da própria dignidade da pessoa humana, para tutelar os valores mais significativos do indivíduo perante outras pessoas ou em relação ao poder público. Pode-se afirmar que, sob o prisma constitucional, os direitos da personalidade passam a expressar o mínimo necessário e imprescindível para uma vida com dignidade.

O aprofundamento internacional da integração econômica, social, política e cultural, denominado "globalização", contribui para a difusão de informações nos dias atuais; a sociedade encontra-se ultraconectada e as informações são facilmente disseminadas através das mídias tradicionais, bem como dos novos métodos desenvolvidos como ferramenta de comunicação e interação.

A revolucionária plataforma da rede mundial de computadores (internet) é sem dúvidas um dos principais mecanismos de disseminação dessas informações (nem sempre verídicas), entretanto, essa nova era social e digital provoca implicações diretas no Direito, ao passo que a Constituição Federal garante aos indivíduos a liberdade de expressão e de imprensa também resguarda os direitos da personalidade e a dignidade da pessoa humana.

Neste contexto questiona-se: existe algum mecanismo jurídico eficaz passível de solucionar os conflitos de normas existentes entre o direito ao esquecimento e o direito à informação? A hipótese é que, a ausência de positivação do direito ao esquecimento e a garantia de outros direitos como a liberdade de expressão e de informação, fazem com que aquele não seja absoluto, podendo ser suscitado em poucas situações.

\section{METODOLOGIA}

O estudo destaca como objetivos (i) apresentar as bases do direito ao esquecimento, quais sejam, os direitos de personalidade e a dignidade da pessoa humana; (ii) apresentar os direitos fundamentais de primeira, segunda e terceira dimensão; (ii) sugerir soluções para solucionar os conflitos do direito ao esquecimento com a liberdade de informação, de expressão e de imprensa.

A pesquisa utilizou-se do método indutivo para aprofundar os conhecimentos acerca do direito ao esquecimento, bem como para buscar meios possíveis de solução dos conflitos 


\section{CONQGEESOO CIENCIAESOCIEDADE

existentes entre normas de mesmo grau hierárquico, com a ajuda de periódicos, doutrinas e posicionamentos jurisprudências para enriquecer e dar respaldo jurídico à problemática levantada.

\section{DIREITO DA PERSONALIDADE VERSUS A DIGNIDADE DA PESSOA HUMANA}

A dignidade da pessoa humana constitui fundamento da República, a Constituição atribuindo-lhe "o valor supremo de alicerce da ordem jurídica democrática". Para Moraes, em todos os setores da vida humana, quando há agressão à sua dignidade, deve tal fato ser objeto de reparação, direta - com a cessação do comportamento; ou indireta - com a aplicação de sanção, no mais das vezes, pecuniária (2003, p.132).

Conforme os supracitados autores, pode-se afirmar que a dignidade da pessoa humana é alicerce para a admissão da existência de pressupostos mínimos para que se possa viver, além do respeito à integridade física, psíquica e intelectual, o respeito às condições fundamentais de liberdade e igualdade, que transcendem o direito à vida. Em outros termos, "o reconhecimento da fundamentalidade do princípio da dignidade da pessoa humana impõe postura aos civilistas modernos, que devem, na interpretação e aplicações de normas e conceitos jurídicos, assegurar a vida humana de forma integral e prioritária" (2016, p.166).

Portanto, a dignidade da pessoa humana é princípio basilar de todo o ordenamento jurídico brasileiro, aparecendo nos mais diversos julgados e jurisprudências, que permeiam as mais diversas áreas do universo jurídico, sendo obrigatório o respeito à sua principiologia, visando, sempre que possível, primar pela sua promoção e proteção.

Os direitos da personalidade, por sua vez, estão relacionados no art. 5o da Constituição Federal e no Código Civil de 2002, em capítulo próprio, iniciando no art. 11 indo até o art. 21. No caput do art. 11 pode-se ler que, "com exceção dos casos previstos em lei, os direitos da personalidade são intransmissíveis e irrenunciáveis, não podendo o seu exercício sofrer limitação voluntária". Logo, vê-se que o diploma civil não destoa do que já dispõe o discurso constitucional a respeito do direito à vida, à liberdade, à igualdade, à segurança e à propriedade, os quais inspira e acolhe. 
Neste sentido, a primeira Jornada de Direito Civil, através da sua 4a proposição afirma que "o exercício dos direitos da personalidade pode sofrer limitação voluntária, desde que não seja permanente e muito menos geral".

Os direitos da personalidade possibilitam a atuação na defesa da própria pessoa, considerada em seus aspectos físico, psíquico, intelectual etc. Compõe, na realidade, um conjunto de vantagens jurídicas reconhecidas à pessoa, referentes aos seus diferentes aspectos em si mesma e às suas projeções e aos prolongamentos (FARIAS; ROSENVAL, 2016, p. 176).

Nesse contexto, observa-se que os direitos da personalidade têm por objeto os modos de ser, físicos ou morais do indivíduo. O que se busca proteger com tais direitos são os atributos específicos da personalidade, sendo esta a qualidade do ente considerado pessoa. Em síntese, pode-se afirmar que os direitos da personalidade são aqueles inerentes à pessoa e à sua dignidade

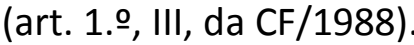

\section{DIMENSÕES DE DIREITOS}

A doutrina dos direitos do homem tem avançado bastante desde o seu surgimento nos séculos XVII e XVIII, sendo o seu ponto de origem a Declaração dos Direitos Humanos e do Cidadão, em 1789, vinculada aos movimentos que circunscreveram o período da Revolução Francesa. E, embora ainda se presencie a luta constante pela efetivação e garantia dos tais direitos, é cediço que a maioria deles já foi solidificado na vida das pessoas, cada etapa percorrida nos anos remotos sendo de salutar importância para consolidação dos mesmos e das quais não se pode facilmente voltar atrás (BOBBIO, 1992).

Dentro do ordenamento jurídico brasileiro, alguns desses direitos encontram-se positivados no art. 50 da Constituição Federal de 1988, a exemplo dos princípios da liberdade e da igualdade, que serviram de base para a Revolução Francesa, são mencionados no caput do referido artigo, e que sem eles, não existiriam os demais direitos.

Por sua vez, como desdobramentos da liberdade e igualdade que são possuidores todos os cidadãos, fala-se atualmente em, pelo menos, quatro dimensões de direitos fundamentais. Na primeira dimensão, como reflexo do movimento constitucionalista do século XVIII, enaltece os valores fundamentais da pessoa humana, com a exigência da constatação dos direitos básicos sem os quais a pessoa humana não pode ser concebida como pessoa, entre os quais pode-se citar a 


\section{CONQEBESSO CIENCIAESOCIEDADE

liberdade, a propriedade, a vida, a segurança, o direito de reunião, dentre outros (VIEIRA, 2007, p. 36).

Já na segunda geração, de acordo com Vieira (2007) os direitos ressaltam as novas conquistas do homem, atendendo a um anseio geral de confirmação do indivíduo como pessoa cultural, socialmente atuante e economicamente ativa. Os prejuízos provocados pelas duas grandes Guerras Mundiais contribuíram para uma nova forma de pensar o indivíduo dentro de uma nova proporção de direitos fundamentais, garantindo-lhe direitos como saúde e trabalho (VIEIRA, 2007, p. 37).

A terceira geração de direitos fundamentais vai muito além dos valores salvaguardados nas duas primeiras gerações, já que não reconhece exclusivamente o indivíduo em si mesmo, nem aprova apenas as conquista sociais. Esta dimensão de direitos fundamentais destaca o conceito humanitário, enfatizando a adequação dos valores reconhecidos pela experiência humana decorrente da nova dinâmica social, econômica e cultural, assim, protege o homem "em uma concepção universal, sendo consagrados os direitos à paz, ao desenvolvimento, ao consumo, ao meio ambiente, à comunicação" (VIEIRA, 2007, p. 36).

Embora já se fale, no século XXI, em uma 5a , 6a e 7ạ dimensão de direitos, para o presente trabalho é oportuno citar até a quarta dimensão que, para Novelino, compreendiam o futuro da cidadania e correspondem à institucionalização do Estado social, sendo relevantes para a realização e legitimidade da globalização política, responsável por incorporar, no âmbito jurídico, os direitos à democracia, à informação e ao pluralismo.

Neste sentido, a incorporação de novas dimensões de direitos fundamentais indica o caráter dinâmico e histórico-evolutivo da própria história humana, ainda que, em essência, esses novos direitos conservem uma ligação mais ou menos direta com os três valores tradicionais, quais sejam, a liberdade, igualdade e fraternidade.

\subsection{Do direito a informação}

Como consequência do Estado Democrático de Direito, e assegurado pela Constituição Federal de 1988, o direito à informação detém o status de direito fundamental, tendo em vista que este decorre diretamente do direito à liberdade de expressão, parte de um conjunto de garantias que visam assegurar a liberdade de comunicação. 
A Constituição ora vigente assegura expressamente o direito à informação em seu artigo 5o, inciso XIV, complementando-o ainda pelo caput do art. 220, que garante a inexistência de censura na informação jornalística, não se podendo falar em restrições na busca e transmissão de informações, desde que respeitado os limites impostos pela Carta Magna também em seu art.5o, XXXIII, que contém a matéria considerada sigilosa.

Portanto, a garantia da liberdade de expressão possibilita a divulgação do pensamento e da informação por diversos meios, dentre eles o jornalismo, o rádio, a televisão e, especialmente, a internet. Por sua vez, a garantia dessa liberdade destina-se a tutelar o direito de externar todo tipo de manifestação do pensamento humano. Engloba, também, em seu conteúdo, além da comunicação de pensamentos e de informações, expressões não verbais, tais como expressões comportamentais, musicais e por imagem.

A liberdade de informação e de expressão podem ser classificadas como direitos subjetivos fundamentais assegurados a todo cidadão, cristalizadas na faculdade de se manifestar de forma completamente livre o pensamento, as ideias e opiniões através de qualquer meio de comunicação, assim como no direito de comunicar ou receber informação verdadeira, consistindo em liberdades indispensáveis ao exercício da democracia e ao desenvolvimento dos povos.

Vale ressaltar, ainda, que a garantia à liberdade de informação transcende as fronteiras brasileiras, sendo pauta, inclusive, na Declaração Universal dos Direitos Humanos e na Convenção Americana de Direitos Humanos, também conhecida como Pacto de San José da Costa Rica.

\subsection{Da liberdade de imprensa}

Também albergada constitucionalmente, a liberdade de imprensa é vertente da liberdade de expressão e de informação. A partir daí pode-se dizer que a liberdade de imprensa concentra tanto a liberdade de informar, como também através dela é que se realiza a liberdade de ser informado.

Em uma sociedade globalizada, não resta dúvidas do poder da liberdade de imprensa na formação da opinião, é clara a influência da imprensa em todos os setores sociais, sendo por vezes conhecida como quarto poder, de acordo com Dotti (1980, p. 129).

Tamanha foi a preocupação do legislador em garantir a liberdade de imprensa que no texto constitucional reservou todo um bloco normativo, intitulado "Da Comunicação Social" (capítulo V do título VIII). 
É fato que nem todos concordam com a nomenclatura "quarto poder" por vezes atribuída à imprensa. Todavia, é nítida sua força e influência sendo esta de suma importância no desenvolvimento e fortalecimento de qualquer Estado de Direito que tenha a pretensão de se auto afirmar como democrático. Podendo-se até aferir que o grau de liberdade de um povo pode ser medido pela amplitude conferida ao seu direito de manifestar o pensamento por todas as formas e por uma imprensa livre.

\subsection{Da liberdade de expressão}

A liberdade de expressão constitui característica da natureza racional do indivíduo e é um conceito fundamental nas democracias modernas. Consiste no direito de qualquer um manifestar livremente opiniões, ideias e pensamentos pessoais sem medo de retaliação ou censura por parte do governo ou de outros membros da sociedade.

Durante a Era Vargas, o Brasil conheceu a censura, que fora adotada como um meio de impedir a publicação ou a reprodução de determinadas informações, surgindo com uma única finalidade: reprimir a liberdade de expressão. A edição da Lei 2.083 de 1953, conhecida como lei de imprensa, ainda na gestão de Vargas, fez o Brasil regredir no que diz respeito à liberdade de expressão, uma vez que esta lei trazia em seu corpo trazia a regulamentação dos crimes de imprensa. Mais tarde, sobre ela recaiu a ADPF 130 que proferiu a sua total inconstitucionalidade.

Com a Constituição Federal de 1988 a sociedade brasileira conheceu muitas inovações acerca da liberdade de manifestação do pensamento, sendo a mesma tratada no texto constitucional como um direito fundamental e intransferível, inerente a todas as pessoas e um requisito para a existência de uma sociedade democrática, não podendo ser ferida sob pena de se estar ferindo o Estado Democrático de Direito. ${ }^{6}$

\subsection{Da privacidade, da honra e da intimidade}

A Constituição Federal de 1988 trouxe a expressa garantia dos direitos à privacidade, à honra e à intimidade, sendo vedada qualquer conduta que atente a tais garantias constitucionais. Os direitos acima citados também estão elencados no art. 5ㅇ, X da Carta Magna, in verbis: "X - são

\footnotetext{
${ }^{6}$ A própria Declaração Universal dos Direitos Humanos, de 1948, positiva a liberdade de expressão em seu artigo XIX: "Todo o indivíduo tem direito a liberdade de opinião e de expressão, o que implica o direito de não ser inquietado pelas suas opiniões e o de procurar, receber e difundir, sem consideração de fronteiras, informações e ideias por qualquer meio de expressão".
} 
invioláveis a intimidade, a vida privada, a honra e a imagem das pessoas, assegurado o direito a indenização pelo dano material ou moral decorrente de sua violação".

Desse modo, em conformidade com a expressa previsão legal o titular de tal direito é dotado de determinadas faculdades jurídicas que são garantidas através de normas. Sobre a norma constante no art. 5ำ X da Constituição Federal de 1988.

Desta feita, pode-se observar que no Brasil os direitos à privacidade, à honra e à intimidade, são assegurados a todos os indivíduos sendo vedado qualquer ato atentatório a tais garantias, inclusive a divulgação de informações verídicas ou não que não sejam de interesse público e que podem gerar danos irreparáveis às vítimas.

\section{CONFLITOS DE DIREITOS}

Em diversas situações coloca-se a decidir o que é mais importante, se o direito de determinada pessoa ou o direito de outra, na ciência jurídica os confrontos envolvendo essas circunstancias é sua própria essência. Também são comuns as situações onde se precisa decidir entre o predomínio de determinado direito fundamental sobre o outro, tendo em vista os diferentes direitos fundamentais protegidos pela Constituição Federal.

Nesse contexto, podem ser observados os conflitos existentes entre esses direitos, onde em determinadas situações tem-se que decidir por um determinado direito sem ofender o outro.

\subsection{Do direito ao esquecimento}

Um instituto relativamente novo é o direito ao esquecimento, que deriva diretamente dos direitos da personalidade e se encontra nitidamente amparado no princípio da dignidade da pessoa humana. Conforme leciona Cavalcante "é o direito que uma pessoa possui de não permitir que um fato, ainda que verídico, ocorrido em determinado momento de sua vida, seja exposto ao público em geral, causando-Ihe sofrimento ou transtornos" (2014, p.198).

O direito ao esquecimento também é conhecido como o direito de ser deixado em paz ou direito de estar só, possui a proteção dos direitos decorrentes da personalidade, violá-lo não significa disseminar informações inverídicas e nem tão pouco fatos inéditos, pois estes podem ser repetidos inúmeras vezes, provocando na vítima um mal estar pessoal e social que ferirá diretamente a sua intimidade (GRECO, 2013 p.761). 
O julgamento, pelo Tribunal Constitucional Alemão, do "caso Lebach" deu notoriedade ao direito ao esquecimento. No caso em questão, uma emissora pretendia documentar o ato criminoso e foi proibida pelo Tribunal Constitucional Alemão em virtude do grande lapso temporal decorrido após o caso, do cumprimento de pena de um dos responsáveis pelo crime, bem como dos enormes prejuízos que a divulgação do documentário iria acarretar ao autor da demanda. Pode-se notar que no caso em questão foi aplicado o princípio da proteção da personalidade em detrimento da liberdade de informação visando minimizar os prejuízos que a emissão do documentário iria causar a vida do autor.

Dessa forma, conclui-se que no ordenamento jurídico brasileiro, a divulgação de informações de fatos ocorridos há um determinado tempo, expondo a imagem dos envolvidos à época, ou informações que comprometem e facilitam suas identidades, ao mesmo tempo em que encontra amparo na liberdade de informação, também encontra vedação nos direitos à privacidade, à honra e à intimidade.

Existe a possibilidade de solucionar esse conflito de normas e princípios constitucionais de forma efetiva? Considerar que o nosso ordenamento jurídico é uma "unidade sistemática" (BOBBIO, 1996, p.73) e que, portanto, deve-se aplicar a ponderação sem sombra de dúvidas é uma solução harmônica para o aparente conflito existente.

Portanto, nos casos em que há aparente conflito entre o direito à informação e os direitos da personalidade, deve-se ponderar, e apenas dar publicidade às informações em torno das quais haja interesse público atual, explanando apenas o indispensável, preservando os dados íntimos e as informações que já tenham deixado de atrair notoriedade.

O Superior Tribunal de Justiça proferiu duas importantes decisões acerca do direito ao esquecimento. No ano de 2013, uma sobre o caso da "chacina da candelária" (REsp 1.334.097) onde o entendimento do Tribunal de superposição foi no sentido de condenar uma emissora ao pagamento de danos morais em virtude da violação do direito ao esquecimento de um dos envolvidos do caso que teve seu nome e imagem divulgados mesmo após muitos anos do crime onde este fora inclusive absolvido. A outra decisão, sobre o caso "Aída Curi" (REsp 1.335.153), teve julgamento inverso, pois no entender do tribunal, em se tratando de fato histórico dotado de interesse público, não há o que se falar em violação do direito ao esquecimento.

É cristalino que a interpretação sistemática e o juízo de ponderação levam à conclusão de que os indivíduos devem ter assegurado o direito ao esquecimento, visto que tal direito deriva 


\section{CONGEESSO CIENCIAESOCIEDADE \\ Inovação, Diversidaale e Sustentalililitadie}

diretamente dos direitos da personalidade que são garantias fundamentais, bem como da base do Estado Democrático de Direito e, por consequência, da dignidade da pessoa humana.

Tal proteção não implica dizer que todos os fatos estão amparados por esse direito ao esquecimento, devendo ser ressalvados os fatos genuinamente históricos, cujo interesse público permaneça mesmo com o decorrer do tempo, desde que a narrativa não tenha como ser desvinculada dos envolvidos.

\subsection{A aplicação do direito ao esquecimento na sociedade da informação}

O equilíbrio entre a liberdade de informação e o direito à privacidade tem gerado, nos últimos anos, significativo debate ao redor do mundo. Embora o tema não seja novo, com o crescente progresso tecnológico vem-se clamando por uma abordagem atualizada e por uma análise diferenciada.

Por vezes o direito ao esquecimento é associado ao âmbito penal, porém este tem sido visualizado em outras áreas e possui proteção constitucional. Com as novas tecnologias de informação e diante da vulnerabilidade da privacidade dos indivíduos este tem sido abordado na defesa dos cidadãos.

A partir da exposição dos direitos fundamentais resta claramente demonstrada a importância da ponderação no caso concreto, pois ainda que o direito ao esquecimento seja constitucionalmente amparado, há limites para o seu exercício não devendo este se sobrepor ao direito à liberdade de expressão, de informação e liberdade de imprensa que por sua vez também possuem limites.

Diante das polêmicas, verifica-se que o direito de ser esquecido não é absoluto, sua aplicação dependerá do caso concreto e da comprovação da violação dos direitos subjetivos do individuo. Nesse caso, pode-se afirmar que a solução para os conflitos dos direitos da primeira dimensão se encontram na proporcionalidade, ponderação e na razoabilidade.

\section{CONSIDERAÇÕES FINAIS}

Após o estudo, considera-se que a ponderação, proporcionalidade e razoabilidade devem ser consideradas de acordo com as normas e procedimentos legais, na solução de conflitos entre os direitos fundamentais de primeira dimensão. Estes por sua vez exaltam os valores 


\section{CONGQEESSOCIENCIAESOCIEDADE

fundamentais da pessoa humana, com a condição da constatação dos direitos básicos, sem os quais a pessoa humana não pode ser considerada como pessoa.

Contudo, ainda é frequente a luta pela efetivação e garantia dos direitos, e um deles é o direito ao esquecimento que não confere à pessoa o direito de fazer desaparecer fatos relacionados a ela, mas somente garante a possibilidade de debater o que deve ser publicado a seu respeito, assim como o modo e a finalidade com que são lembrados. Na sociedade democrática em que se vive o direito à informação passa, assim, a ser considerado um direito fundamental, havendo uma relação direta entre a cidadania e a obtenção de informações, estando este direito contido na Carta Magna, desde sua publicação em 1988.

No entanto, deve ser ressaltado que toda a informação transmitida deve acontecer de forma séria, criteriosa e verdadeira, considerado os preceitos éticos para que o leitor consiga entender a importância da relação entre informação e sociedade, procurando informar sem interferir na dignidade da pessoa humana.

\section{REFERÊNCIAS}

ADPF 130, Relator Ministro Carlos Brito, Dje $n^{\circ}$ 208, 06/11/2009, Disponível em http://redir.stf.jus.br/paginadorpub/paginador.jsp?docTP=AC\&doclD=605411. Acesso em 02 de Março de 2018.

BASTOS, Celso Ribeiro. A Constituição na visão dos tribunais - Interpretação e Julgados - Artigo por Artigo. Vol. I. Brasília: Editora Saraiva, 1997.

BOBIO, Norberto. A era dos direitos. Rio de Janeiro: Campus, 1992.

. Norberto. Teoria do ordenamento jurídico. UNB, 1996.

BRASIL, DIREITOS DA PERSONALIDADES, Disponível em:

<https://www.jusbrasil.com.br/jurisprudencia/busca?> Acesso em: 8 de mai.2018.

, Supremo Tribunal Federal. Brasília, 29 de setembro de 2014. Disponível em:

$<$ http://www.stf.jus.br/portal/cms/verNoticiaDetalhe.asp?idConteudo=276284>, Acesso em: 8 de mai.2018.

, Superior Tribunal de Justiça (STJ), 10 de Setembro de 2013. Disponível em:

<https://www.jusbrasil.com.br/diarios/58894349/stj-10-09-2013-pg-2577> Acesso em: 5 de jun.2018. 
Constituição da República Federativa do Brasil de 1988. Disponível em:

<http://www.planalto.gov.br/ccivil 03/constituicao/constituicaocompilado.htm > Acesso em: 5 de jun.2018.

Código Civil 2002. Da aplicação do dano moral como meio de efetiva proteção às violações ao Direito de Imagem em razão de ofensas perpetradas em redes sociais. Disponível em: <http://www.planalto.gov.br/ccivil 03/Leis/2002/l10406.htm> Acesso em: 5 de jun.2018.

Conselho da Justiça Federal. Direito ao esquecimento é garantido por turma do STJ.

Disponível em: <http://www.cjf.jus.br/enunciados/pesquisa/resultado > Acesso em: 4 de jun.2018.

CAVALCANTE, Márcio André Lopes. Principais julgados do STF e do STJ comentados. Manaus: Dizer o Direito, 2014.

COSTA JUNIOR, Paulo José. Agressões à intimidade. São Paulo: Malheiros, 1997.

DECLARAÇÃO UNIVERSAL DOS DIREITOS HUMANOS. 1948. Disponível em: <www.unicef.org/brazil/pt/resources 10133.htm > Acesso em 30 de novembro de 2017.

DOTTI, René Ariel. Proteção da vida privada e liberdade de informação. São Paulo: Revista dos Tribunais, 1980.

FARIAS, Cristiano Chaves de.; ROSENVAL, Nelson. Curso de direito civil parte geral e LINDB. 14. ed. Salvador: JusPodivm, 2016.

GRECO, Rogério. Principiologia penal e garantia constitucional à intimidade. In: Temas Atuais do Ministério Público. 4 ed. Salvador: Jus Podvm, 2013.

JUSBRASIL, Jurisprudência. Busca unificada com inteiro teor de acórdãos. Disponível em: <https://www.jusbrasil.com.br/jurisprudencia/busca?> Acesso em: 5 de jun. 2018.

MALDONADO, Viviane Nóbrega. Direito ao esquecimento. São Paulo: Novo século, 2017.

MORAES, Maria Celina Bodin de. Danos à pessoa humana. Rio de Janeiro: Renovar, 2003.

NOVELINO, Marcelo. Curso de direito constitucional. 12. ed. rev. ampl. e atual. Salvador: Ed. JusPodivim, 20017.

ROMANO, Rogério Tadeu. Direito ao esquecimento e liberdade de imprensa. (2017) Disponível em: <https://jus.com.br/artigos/59942/direito-ao-esquecimento-e-liberdade-de-imprensa> Acesso em: 9 de mai.2018.

TARTUCE, Flávio. Manual de direito civil: Volume único. 4. ed. Rio de Janeiro: Forense, 2014.

VIEIRA, Felipe. Comentários à constituição. 3. ed. Rio de Janeiro: Ed. Ferreira, 2007. 